\title{
Papers
}

\section{Effectiveness and economic evaluation of a nurse delivered home exercise programme to prevent falls. 2: Controlled trial in multiple centres}

\author{
M Clare Robertson, Melinda M Gardner, Nancy Devlin, Rob McGee, A John Campbell
}

\begin{abstract}
Objectives To assess the effectiveness of trained nurses based in general practices individually prescribing a home exercise programme to reduce falls and injuries in elderly people and to estimate the cost effectiveness of the programme.

Design Controlled trial with one year's follow up. Setting 32 general practices in seven southern New Zealand centres.

Participants 450 women and men aged 80 years and older.

Intervention 330 participants received the exercise programme (exercise centres) and 120 received usual care (control centres); 87\% (371 of 426) completed the trial.

Main outcome measures Number of falls, number of injuries resulting from falls, costs of implementing the programme, and hospital costs as a result of falls. Results Falls were reduced by $30 \%$ in the exercise centres (incidence rate ratio $0.70,95 \%$ confidence interval 0.59 to 0.84 ). The programme was equally effective in men and women. The programme cost \$NZ418 (£121) (at 1998 prices) per person to deliver for one year or $\$ N Z 1519$ (£441) per fall prevented. Fewer participants had falls resulting in injuries, but there was no difference in the number who had serious injuries and no difference in hospital costs resulting from falls in exercise centres compared with control centres.

Conclusions An individually tailored exercise programme, delivered by trained nurses from within general practices, was effective in reducing falls in three different centres. This strategy should be combined with other successful interventions to form part of home programmes to prevent falls in elderly people.
\end{abstract}

\section{Introduction}

Three questions need to be addressed in the development and evaluation of a public health intervention: "can it work?”, "does it work in practice?", and "is it worth it?"1 Our research group considered the efficacy, effectiveness, and efficiency of a home based, individually tailored, muscle strengthening and balance retraining programme, designed to prevent falls in elderly people living in the community.

We tested the exercise programme in a group of women aged 80 years and older and showed it could work. $^{2}$ The numbers of falls and falls resulting in moderate injuries were reduced when the exercise programme was delivered by a physiotherapist from the research group. The reduction in falls continued during a second year of follow up. ${ }^{3}$

In this paper we report the results from the second of two pragmatic trials designed to test the effectiveness and efficiency of the same exercise programme in routine clinical practice. In this trial the programme was delivered from general practices by trained practice nurses to men and women aged 80 years and older. We initiated the trial as a health promotion exercise to evaluate the processes involved and to determine whether the exercise programme would be as effective in reducing falls in the wider community as it had been for women in the initial trial in a research setting.

\section{Participants and methods}

\section{Participant recruitment}

We identified potential participants aged 80 years and older from computerised registers at 32 general practices (56 doctors) in seven southern New Zealand centres. These patients received a letter from their doctor inviting them to take part in the study. The criteria for exclusion were inability to walk around own residence, receiving physiotherapy at the time of recruitment, or not able to understand the requirements of the trial. Recruiting took place over a six month period in 1998.

\section{Trial design}

This was a controlled trial, with one year's follow up. The sample size calculation was based on the proportion of elderly people who fell once or more in a 12 month prospective study in the community, ${ }^{4}$ an expected reduction from 0.50 to 0.30 , and allowance for the multicentre design, the Poisson type distribution of falls, and a $20 \%$ dropout rate. Our study was approved by the ethics committees of the Southern Regional Health Authority Otago and Southland.

\author{
Department of \\ Medical and \\ Surgical Sciences, \\ Otago Medical \\ School, PO Box \\ 913, Dunedin, \\ New Zealand \\ M Clare Robertson \\ research fellow \\ Melinda M Gardner \\ research \\ physiotherapist \\ A John Campbell \\ professor of geriatric \\ medicine \\ Department of \\ Economics, \\ University of Otago \\ Nancy Devlin \\ senior lecturer \\ Department of \\ Preventive and \\ Social Medicine, \\ Otago Medical \\ School \\ Rob McGee \\ senior lecturer \\ Correspondence to: \\ M Clare Robertson \\ clare.robertson@ \\ stonebow.otago.ac.nz
}

BMJ 2001;322:1-5 
Table 1 Characteristics of participants at entry to trial. Values are numbers (percentages) unless stated otherwise

\begin{tabular}{|c|c|c|c|c|}
\hline \multirow[b]{2}{*}{ Characteristic } & \multirow{2}{*}{$\begin{array}{l}\text { Control } \\
\text { centres } \\
(\mathrm{n}=120)\end{array}$} & \multicolumn{3}{|c|}{ Exercise programme centres } \\
\hline & & $1(n=115)$ & $2(n=120)$ & $3(n=95)$ \\
\hline Mean (SD) age (years) & $84.2(3.1)$ & $82.7(2.5)$ & $83.6(2.8)$ & $84.1(3.0)$ \\
\hline$\overline{M e n}$ & $35(29)$ & $32(28)$ & $37(31)$ & $32(34)$ \\
\hline \multicolumn{5}{|l|}{ Living arrangements: } \\
\hline Two or more participants in one home & $20(17)$ & $26(23)$ & $24(20)$ & $12(13)$ \\
\hline Living alone & $74(62)$ & $64(56)$ & $76(63)$ & $56(59)$ \\
\hline Living in nursing home & - & $1(1)$ & $2(2)$ & - \\
\hline Fallen in previous year & $55(46)$ & $47(41)$ & $54(45)$ & $53(56)$ \\
\hline \multicolumn{5}{|l|}{ Medical conditions: } \\
\hline Parkinson's disease & $3(3)$ & $2(2)$ & $1(1)$ & $1(1)$ \\
\hline Stroke & $16(13)$ & $15(13)$ & $18(15)$ & $12(13)$ \\
\hline Hip fracture & $3(3)$ & $2(2)$ & $8(7)$ & $3(3)$ \\
\hline Knee or hip pain, or both & $34(28)$ & $34(30)$ & $39(33)$ & $25(26)$ \\
\hline \multicolumn{5}{|l|}{ Mean (SD) scores on SF-12*: } \\
\hline Physical component & $42.0(10.2)$ & $43.1(10.0)$ & $40.1(11.0)$ & $42.4(11.6)$ \\
\hline Mental component & $56.4(4.5)$ & $55.6(5.0)$ & $55.1(5.7)$ & $54.1(6.6)$ \\
\hline Mean (SD) No of current prescribed drugs & $3.0(2.1)$ & $2.7(2.0)$ & $3.8(2.1)$ & $2.6(1.8)$ \\
\hline Taking psychotropic drugs & $16(13)$ & $4(4)$ & $13(11)$ & $17(18)$ \\
\hline \multicolumn{5}{|l|}{ Home assistance: } \\
\hline Cleaning & $47(39)$ & $47(41)$ & $49(41)$ & $34(36)$ \\
\hline Showering & $9(8)$ & $3(3)$ & $4(3)$ & $10(11)$ \\
\hline Meals on wheels & $16(13)$ & $7(6)$ & $16(13)$ & $10(11)$ \\
\hline
\end{tabular}

*Score ranges $0-100$, lower scores indicate poorer health.

We chose three centres as exercise centres and a similar mix of four towns to act as control centres. The 120 participants in the control centres were required to indicate that they would be willing to receive the exercise programme if it was offered. After written informed consent was obtained and baseline assessments (personal characteristics, health, and function) completed at home by an independent assessor, the 330 participants in the exercise centres received the muscle strengthening and balance retraining programme.

\section{Intervention}

The three nurses from the exercise centres received the same training and implemented the same exercise programme as in the accompanying article. ${ }^{5}$ For the delivery of the programme the nurses were employed part time on research funding. In addition to supervision by the physiotherapist the nurses attended team meetings at the supervising centre on four occasions to discuss progress and any problems and to compare experiences.

Measurement of falls and injuries and health status Fall events were defined and monitored for one year and the severity of injury categorised as described in the accompanying article. ${ }^{5}$ The nurse or independent assessor in each centre telephoned participants to record the circumstances of the falls and any injuries or resource use as a result of the falls. The SF-12 questionnaire was used to estimate self perceived health status at entry to the trial. ${ }^{6}$

\section{Methods used in economic evaluation}

The methods used in the economic evaluation are detailed in the accompanying paper. ${ }^{5}$ We report costs in 1998 New Zealand dollars, exclusive of government goods and services tax.

Assuming that participants keep exercising, the benefits of the exercise programme would extend past the time individuals participated in the trial, but the extent of this benefit and longer term compliance rates are uncertain. We calculated cost effectiveness ratios for the duration of the trial only.

\section{Statistical analysis}

We analysed data with the same methods as in the accompanying article. ${ }^{5}$ Four participants in the exercise centres completed the baseline assessments but did not receive any visits (one died, a spouse died, and two were no longer interested). The mean (SD) time between the baseline assessment and the first home visit for the exercise programme was 17.0 (14.0) days. We analysed data on an intention to treat basis with Stata Release 6 and SPSS 6.1.1.

We compared the number of falls and the number of falls resulting in injuries (moderate or serious) in the exercise and control centres using negative binomial regression models, adjusting standard errors for clustering on centre. ${ }^{7}$ These models estimate the number of occurrences of an event when the event has Poisson variation with overdispersion, and they allow for variable follow up times for participants and investigation of the treatment and interaction effects.

We present unadjusted results for the remainder of the outcome variables because the numbers of events were low and the within centre correlation is likely to have little effect. We used Student's $t$ test to compare means and Fisher's exact test or $c^{2}$ test to compare proportions between groups.

\section{Results}

\section{Trial participants and follow up}

The mean (SD) age of participants was 83.7 (2.9) years, and ages ranged from 79 to 94 years. The participants in both groups were well matched on characteristics at entry to the trial (table 1).

\begin{tabular}{|c|c|c|c|c|}
\hline \multirow{3}{*}{$\begin{array}{l}\text { Approved by doctor } \\
\text { and invited to participate }\end{array}$} & ontrol centres & \multicolumn{3}{|c|}{ Exercise centres } \\
\hline & \multirow[b]{2}{*}{$(n=281)$} & 1 & 2 & 3 \\
\hline & & $(n=257)$ & $(n=232)$ & $(n=219)$ \\
\hline $\begin{array}{l}\text { Chose not to participate, } \\
\text { not eligible, could not be }\end{array}$ & $(n=161)$ & $(n=142)$ & $(n=112)$ & $(n=124)$ \\
\hline Baseline assessments & & $(n-115)$ & $(n-120)$ & $(n-95)$ \\
\hline & & & & \\
\hline $\begin{array}{l}\text { Did not start exercise } \\
\text { programme }\end{array}$ & & $(\mathrm{n}=0)$ & $(n=3)$ & $(n=1)$ \\
\hline Withdrew from exercise & & & & \\
\hline programme only: & & $(n=7):$ & $(n=15):$ & $(n=11):$ \\
\hline Fall injury & & $(n=0)$ & $(\mathrm{n}=1)$ & $(\mathrm{n}=0)$ \\
\hline $\begin{array}{l}\text { Health problem } \\
\text { Not interested }\end{array}$ & & $(n=1)$ & $(n=10)$ & $(\mathrm{n}=6)$ \\
\hline $\begin{array}{l}\text { Not Interested } \\
\text { Didn't like exercise }\end{array}$ & & $\begin{array}{l}(n=5) \\
(n=1)\end{array}$ & $\begin{array}{l}(n=4) \\
(n=0)\end{array}$ & $\begin{array}{l}(n=4) \\
(n=1)\end{array}$ \\
\hline Withdrew from trial: & $(n=14):$ & $(n=24)$ : & $(n=15):$ & $(n=26):$ \\
\hline Died & $(n=9)$ & $(n=3)$ & $(\mathrm{n}=7)$ & $(n=5)$ \\
\hline Fall injury & $(\mathrm{n}=0)$ & $(\mathrm{n}=1)$ & $(n=0)$ & $(\mathrm{n}=0)$ \\
\hline Health problem & $(n=2)$ & $(n=15)$ & $(n=4)$ & $(\mathrm{n}=12)$ \\
\hline Not interested & $(\mathrm{n}=3)$ & $(n=2)$ & $(n=1)$ & $(\mathrm{n}=7)^{\prime}$ \\
\hline Didn't like exercise & & $(n=2)$ & $(n=0)$ & $(\mathrm{n}=1)$ \\
\hline Other & $(\mathrm{n}=0)$ & $(n=1)$ & $(n=3)$ & $(\mathrm{n}=1)$ \\
\hline Assessments at 1 year & $(\mathrm{n}=101)$ & $(n=90)$ & $(n=103)$ & $(n=68)$ \\
\hline Completed trial (falls & $(n=106)$ & $(\mathrm{n}=91)$ & $(n=105)$ & $(n=69)$ \\
\hline
\end{tabular}

Flow of participants through trial 
The figure shows the flow of participants through the trial. The results of assessments repeated at one year will be reported separately. More participants from the control centres than the exercise centres completed the trial $(88 \%$ v 80\%, $\mathrm{P}=0.066)$.

Overall, $43 \%$ (114 of 265) of participants who completed the trial carried out their prescribed exercise programme three or more times a week, $62 \%(n=164)$ completed their exercise programme at least twice a week, and $63 \%(\mathrm{n}=167)$ walked at least twice a week during the one year.

Three adverse events were reported. One person stopped exercising and visited her doctor with pain due to the exercises, and two people fell while exercising, one pulling a muscle. One person walked backwards into a stool, and one collapsed while walking sideways.

\section{Falls and fall related injuries}

Table 2 shows the actual and standardised numbers of falls and the numbers of falls resulting in injuries during the trial. A significant reduction was found in the numbers of falls during the trial for the exercise centres compared with the control centres (incidence rate ratio from negative binomial regression model $0.70,95 \%$ confidence interval 0.59 to 0.84 ). This $30 \%$ reduction in falls was similar for both men and women.

Fewer falls in the exercise centres resulted in an injury (moderate or serious) than the control centres (incidence rate ratio $0.72,95 \%$ confidence interval 0.62 to 0.82 ). No difference was found between the numbers of participants with serious injuries (15 of 330 in exercise centres versus 2 of 120 in control centres, $\mathrm{P}=0.261)$. Eight falls resulted in fractures and three in lacerations requiring sutures.

\section{Economic evaluation}

Costs of implementing the exercise programme-The exercise programme cost $\$ N Z 137878$ or $\$ N Z 418$ per person to deliver to the 330 participants in the exercise centres for one year.

Resource use and costs resulting from falls-Overall, 71 of $303(23 \%)$ falls resulted in the use of healthcare services (table 2). No significant difference was found in the numbers of hospital admissions as a result of a fall injury (12 in total) between the exercise and control centres. The difference between the actual cost of these hospital admissions for participants from the exercise $(\$ N Z 50470)$ and control centre $(\$ N Z 10993)$ as a result of a fall was not significant $(\mathrm{P}=0.584)$.

Cost effectiveness measures-The incremental cost per fall prevented was $\$ N Z 1519$ (table 3). Estimates for the cost per fall with an injury prevented ranged from \$NZ2553 to \$NZ4255 for the different cost scenarios. Table 4 shows the incremental costs of implementing the exercise programme.

We did not include costs from hospital admissions as a result of a fall in the calculation of cost effectiveness ratios as there was no significant difference in these costs, or the number of hospital admissions for exercise and control centres.

\section{Discussion}

Falls can be reduced in men and women aged 80 years and older receiving an exercise programme from trained nurses based in general practices, and this is
Table 2 Incidence of fall events and follow up times in control and exercise programme centres

\begin{tabular}{lcccc} 
& $\begin{array}{c}\text { Control } \\
\text { centres }\end{array}$ & \multicolumn{3}{c}{ Exercise programme centres } \\
\cline { 3 - 5 } & $(\mathbf{n = 1 2 0})$ & $\mathbf{1}(\mathbf{n = 1 1 5 )}$ & $\mathbf{2}(\mathbf{n = 1 2 0 )}$ & $\mathbf{3}(\mathbf{n = 9 5 )}$ \\
\hline No of falls & 105 & 57 & 87 & 54 \\
\hline Falls per 100 person years & 93.9 & 57.4 & 78.4 & 66.4 \\
\hline No of injurious fallst: & 46 & 27 & 37 & 22 \\
\hline Serious & 2 & 3 & 9 & 4 \\
\hline Moderate & 44 & 24 & 28 & 18 \\
\hline Injurious falls per 100 person years & 41.1 & 27.2 & 33.3 & 27.1 \\
\hline No (\%) of falls for which medical care sought & $24(23)$ & $14(25)$ & $24(28)$ & $9(17)$ \\
\hline Mean (SD) follow up time (months) & $11.2(2.6)$ & $10.4(3.4)$ & $11.1(2.8)$ & $10.3(3.3)$ \\
\hline Total follow up time (person years) & 111.83 & 99.38 & 111.03 & 81.29 \\
\hline
\end{tabular}

${ }^{*}$ Incidence rate ratio 0.70 (95\% confidence interval 0.59 to 0.84$), P=0.001$.

†ncidence rate ratio 0.72 ( 0.62 to 0.82$), P=0.001$.

achievable in usual clinical practice. ${ }^{25}$ It was more difficult to gauge whether the exercise programme gave value for money. The programme cost a similar amount per person to deliver as the first pragmatic trial involving a district nurse prescribing the programme, and there were similar estimates for cost effectiveness ratios when the costs of implementing the programme only were considered. Hospital costs were not reduced, however, and therefore the programme was not as cost effective as the first trial. This may be due to the sample sizes used, which were based on falls and not on injury rates, and the fact that the data for hospital costs have a

Table 3 Cost effectiveness ratios and sensitivity analysis: incremental cost of exercise programme per fall event prevented in exercise centres compared with control centres

\begin{tabular}{ll} 
Cost scenario & \$NZ \\
\hline Cost per fall prevented: & \\
\hline Total cost of programme & 1519 \\
\hline 125th centile total cost of programme & 1899 \\
\hline 75th centile total cost of programme & 1139 \\
\hline Training, supervision in same centre & 1426 \\
\hline 125th centile cost of home visits & 1757 \\
\hline$\times 4$ ankle cuff weights & 1856 \\
\hline No extra overhead costs & 1247 \\
\hline Adjusted cost per fall prevented & \\
\hline Total cost of programme & 1734 \\
\hline 125th centile total cost of programme & 2167 \\
\hline 75 th centile total cost of programme & 1300 \\
\hline Training, supervision in same centre & 1627 \\
\hline 125th centile cost of home visits & 2005 \\
\hline$\times 4$ ankle cuff weights & 2117 \\
\hline No extra overhead costs & 1423 \\
\hline Cost per injurious fall prevented: & \\
\hline Total cost of programme & 3404 \\
\hline 125th centile total cost of programme & 4255 \\
\hline 75th centile total cost of programme & 2553 \\
\hline Training, supervision in same centre & 3196 \\
\hline 125th centile cost of home visits & 3937 \\
\hline$\times 4$ ankle cuff weights & 4158 \\
\hline No extra overhead costs & 2794 \\
\hline Adjusted cost per injurious fall prevented & 3808 \\
\hline Total cost of programme & 2885 \\
\hline 125th centile total cost of programme & 3611 \\
\hline Training, supervision in same centre & 4448 \\
\hline No extra overhead costs & 4698 \\
\hline Avth centile cost of home visits & 3157 \\
\hline
\end{tabular}

Average exchange rate in 1998, $\$ N Z 1.00=32 p$.

${ }^{*}$ Calculated using fall events per 100 person years to adjust for variable follow up times for individuals in trial. 


\begin{tabular}{|c|c|c|c|}
\hline Cost item & Resource use & Unit cost (\$NZ) & Total cost (\$NZ) \\
\hline \multicolumn{4}{|l|}{ Training course* } \\
\hline Physiotherapist (hours) & 37.5 & 19.17 & 539 \\
\hline \multicolumn{4}{|l|}{ Three exercise nurses } \\
\hline Time (hours) & 37.5 each & 16.46 per hour & 1852 \\
\hline Travel to Dunedin $(\mathrm{km})$ & 2220 & 0.62 & 1110 \\
\hline Accommodation (nights) $\dagger$ & 5 & 110 & 650 \\
\hline Materials & Folders & 28.21 & 85 \\
\hline Transport in Dunedin & Visits to 15 clients & 0.62 per km & 84 \\
\hline \multicolumn{4}{|c|}{ Recruitment, programme prescription and follow up } \\
\hline Time for 3 nurses & $\begin{array}{c}0.5 \text { equivalent full } \\
\text { time, } 1 \text { nurse } 18 \\
\text { months, } 2 \text { nurses } 19 \\
\text { months }\end{array}$ & Average 16.58 per hour & 67963 \\
\hline Transport for 3 nurses $(\mathrm{km})$ & 4609 & 0.62 & 2858 \\
\hline Doctors' timeł & $\begin{array}{l}46 \text { doctors, } 0.25 \\
\text { hours each }\end{array}$ & 40.39 & 1858 \\
\hline General practice staff time & $\begin{array}{l}26 \text { practices, } 0.75 \\
\text { hours each }\end{array}$ & 13.11 & 341 \\
\hline Typing lists and letters (hours) & 78 & 18.88 & 1473 \\
\hline Postage (stamps) & 768 & 0.40 & 307 \\
\hline Stationery and photocopying & Paper, envelopes & 0.10 & 373 \\
\hline Telephone & $\begin{array}{l}\text { Local calls, } 1 \text { "call } \\
\text { minder," } 2 \text { mobiles }\end{array}$ & & 2676 \\
\hline Ankle cuff weights & 480 & Average 17.40 & 8352 \\
\hline Instruction booklets & 330 folders, paper & 7.50 & 2475 \\
\hline \multicolumn{4}{|l|}{ Supervision of programme } \\
\hline \multicolumn{4}{|l|}{ Physiotherapist: } \\
\hline Time (hours) & 703 & 19.17 & 13484 \\
\hline Travel to centres $(\mathrm{km})$ & 2808 & 0.62 & 1741 \\
\hline Accommodation† & $\begin{array}{l}4 \text { visits to each } \\
\text { centre }\end{array}$ & Average 102.50 & 410 \\
\hline Telephone calls & 108 & Average 6.77 & 731 \\
\hline \multicolumn{4}{|l|}{ Three exercise nurses: } \\
\hline Time & $\begin{array}{l}4 \text { meetings, } \\
\text { telephone calls }\end{array}$ & Average 16.58 per hour & 1607 \\
\hline Telephone calls & 82 & Average 7.11 & 583 \\
\hline Travel to Dunedin $(\mathrm{km})$ & 2586 & 0.62 & 1603 \\
\hline Overhead costs§ & & $21.85 \%$ of resource use & 24724 \\
\hline Total cost & & & 137878 \\
\hline $\begin{array}{l}\text { Average cost per participant for } 1 \\
\text { year programme }\end{array}$ & & & 418 \\
\hline \multicolumn{4}{|c|}{$\begin{array}{l}\text { Average exchange rate in } 1998, \$ N Z 1.00=32 p \text {. } \\
\text { "Costs for training course were divided equally among the four nurses at course (one nurse was from trial } \\
\text { reported in accompanying paper). } \\
\text { †Includes food allowance. } \\
\text { tTime spent by doctors was valued using weighted average price in } 1998 \text { for consultation "person over } 65 \\
\text { without card"; item used in calculation of consumers price index. } \\
\text { \$lncludes office accommodation, financial and administration services, depreciation on equipment. }\end{array}$} \\
\hline
\end{tabular}

skewed distribution. The participants from the exercise centres had fewer moderate injuries as a result of a fall, but no differences were found in the numbers of serious injuries between the two groups.

For the trial of the exercise programme in a research setting, the programme was delivered by a physiotherapist. ${ }^{2}$ We conclude that trained nurses from general practices can also implement the programme successfully. The implementation of the programme worked well from a general practice setting, and because it took up only half the nurses' time it fitted in with other work. Nurses should be trained and supervised by a suitably qualified physiotherapist.

The earlier a health problem can be identified the better. In both our pragmatic trials the nurses acted as patient advocates on several occasions and were able to identify health concerns during the home visits and to deal with them before they became a major problem. It was reassuring that death rates were lower, although not significantly so, in the exercise groups than in the control groups in both trials.

\section{Methodological issues}

As this was a trial of implementing a programme in the community, we used control and exercise centres rather than a randomised controlled design. The pragmatic design ensured that the delivery of the intervention matched as closely as possible what might occur in normal practice using practice nurses. This also avoided contamination as increased public awareness may lead to sharing of information. It is possible that the variable success of the programme in the different centres was influenced by the expertise of the instructor.

Different conditions in different centres may result in different rates of falls. Bias in the findings may have occurred as blinding was not possible except for classifying fall events. It is possible participants in the exercise centres did not want to report falls and disappoint their instructor. However the nurses all developed considerable rapport with the participants, and we believe the effect of this on outcome was minimal.

We investigated only the immediate health related costs and benefits in the economic evaluation, and this resulted in a conservative estimate of cost effectiveness. The benefits of exercising may continue longer than the one year of follow up. In a previous trial we found that reduction of falls continued for two years and involved very little extra use of resources. ${ }^{3}$ In this trial $53 \%$ (139 of 261) of participants completing the exercise programme said they intended to keep exercising, and $41 \%$ chose to keep the ankle cuff weights (from 1 to $8 \mathrm{~kg}$ ). Healthcare costs after a fall may well continue to accrue for the remainder of an individual's life.

\section{Conclusions}

Exercise programmes can prevent falls in elderly people living in the community. ${ }^{8}$ We have also shown that withdrawing psychotropic drugs can prevent falls in people taking these drugs. ${ }^{9}$ Another intervention delivered at home by a health professionalassessment and modification of environmental hazards-has been shown to reduce falls in elderly people who were at increased risk of falling. ${ }^{10} \mathrm{~A}$ home based programme that was individually targeted and multifactorial also reduced falls in elderly people. ${ }^{11}$

We recommend a home based exercise programme delivered by trained nurses. Other components such as awareness of falls, home safety advice, and referral to doctors for reassessment of psychotropic drugs could be included to maximise effectiveness. A programme to prevent falls within general practice is practical, can reduce trauma and help maintain independence, and has the potential to reduce costs due to injury.

We thank the participants; the doctors and their receptionists; Jo Halkett, Rachel Hall, and Jan Muir, exercise instructors; Lenore Armstrong, independent assessor; Graham Arnold, decision support coordinator, HealthCare Otago; Shona Ellis, clinical costing, Southern Health; Irene Henderson, manager, Gore Hospital; Peter Herbison, statistician; Professor Murray Tilyard and the General Practice Research Unit; and Sheila Williams, statistician.

All authors contributed to the study or protocol design, or both, interpreted the data, and wrote the paper. AJC directed the project. MCR managed the project and the data gathering, analysed and interpreted the data, and wrote the paper. MMG trained and supervised the exercise instructor. ND and Dr Paul 


\section{What is already known on this topic}

One half of those aged 80 years and older will fall in any one year, often with serious health and social consequences

An exercise programme delivered by a physiotherapist or trained district nurse was successful in reducing falls and moderate injuries in elderly people

\section{What this study adds}

An exercise programme to prevent falls in elderly people can be delivered safely and effectively by trained nurses in general practices

The nurses obtained results that were consistent with the physiotherapist in the research setting and the district nurse in the accompanying paper

Scuffham advised on the economic evaluation. RM advised on health promotion aspects. AJC and MCR will act as guarantors for the paper.

Funding: This project was funded by Accident Rehabilitation and Compensation Insurance Corporation of New Zealand, the Health Research Council, and Lottery Grants Board, New Zealand. MMG was part funded by a Trustbank Otago Community Trust medical research fellowship.
Competing interests: None declared.

1 Haynes B. Can it work? Does it work? Is it worth it? BMJ 1999;319:652-3.

2 Campbell AJ, Robertson MC, Gardner MM, Norton RN, Tilyard MW, Buchner DM. Randomised controlled trial of a general practice programme of home based exercise to prevent falls in elderly women. BMJ 1997;315:1065-9.

3 Campbell AJ, Robertson MC, Gardner MM, Norton RN, Buchner DM. Falls prevention over 2 years: a randomized controlled trial in women 80 years and older. Age Ageing 1999;28:513-8.

4 Campbell AJ, Borrie MJ, Spears GF. Risk factors for falls in a communitybased prospective study of people 70 years and older. J Gerontol Med Sci 1989;44:112-7M

5 Robertson MC, Devlin N, Gardner MM, Campbell AJ. Effectiveness and economic evaluation of a nurse delivered home exercise programme to prevent falls. 1: Randomised controlled trial. BMJ 2001;322:697-701.

6 Jenkinson C, Layte R, Jenkinson D, Lawrence K, Petersen S, Paice C, et al A shorter form health survey: can the SF-12 replicate results from the SF-36 in longitudinal studies? J Public Health Med 1997;19:179-86.

7 StataCorp. Stata statistical software: release 6.0. College Station, TX: Stata, 1999

8 Gardner MM, Robertson MC, Campbell AJ. Exercise in preventing falls and fall related injuries in older people: a review of randomised controlled trials. BrJ Sports Med 2000;34:7-17.

9 Campbell AJ, Robertson MC, Gardner MM, Norton RN, Buchner DM. Psychotropic medication withdrawal and a home-based exercise program to prevent falls: a randomized, controlled trial. J Am Geriatr Soc 1999;47:850-3.

10 Cumming RG, Thomas M, Szonyi G, Salkeld G, O'Neill E, Westbury C, et al. Home visits by an occupational therapist for assessment and modification of environmental hazards: a randomized trial of falls prevention. J Am Geriatr Soc 1999;47:1397-402.

11 Tinetti ME, Baker DI, McAvay G, Claus EB, Garrett P, Gottschalk M, et al. A multifactorial intervention to reduce the risk of falling among elderly people living in the community. N Engl J Med 1994;331:821-7.

(Accepted 19 December 2000) 